\title{
MATHEMATICAL TOOLS FOR MAXIMISING RENEWABLE ENERGY USE IN ELECTRICITY SUPPLY
}

\author{
ADRIAN GRANTHAM \\ (Received 22 August 2017; first published online 4 December 2017)
}

2010 Mathematics subject classification: primary 00A69.

Keywords and phrases: renewable energy, solar, probabilistic forecasting, storage, synthetic.

In recent years there have been growing concerns over pollution, energy security, rising energy prices and, in particular, how greenhouse gas (GHG) emissions are contributing to climate change. The world's reliance on fossil fuels for generating electricity is unsustainable.

Several studies have shown that it is feasible for Australia and other countries to use renewable energy for $100 \%$ of electricity generation. Many of these studies make simplifying assumptions, such as hourly or daily time scales and low spatial resolution. These assumptions are adequate for first approximations, but are not accurate enough for detailed system design.

This thesis develops methods for creating renewable energy data with realistic variations at high temporal and spatial resolutions and sufficient accuracy for detailed system design.

We address the need for solar irradiance data with high temporal resolution by developing a method for generating synthetic five-minute pairs of global horizontal irradiance (GHI) and direct normal irradiance (DNI), interpolated from hourly mean values. Our method can be applied to locations where only hourly data is available. The results have been published in [3, 4].

We address the need for short-term probabilistic forecasting of solar irradiation. Renewable energy sources such as wind and solar irradiance are inherently intermittent, and so their integration into an electric power grid requires accurate and reliable estimation of uncertainties. We present a new data-driven method for constructing a full predictive density of solar irradiation, based on a nonparametric

Thesis submitted to the University of South Australia in November 2016; degree awarded on 15 June 2017; principal supervisor John Boland, associate supervisors Peter Pudney, Martin Belusko and Lesley Ward.

(C) 2017 Australian Mathematical Publishing Association Inc. 0004-9727/2017 \$16.00 
bootstrap technique. We also develop a method for spatio-temporal probabilistic forecasting of wind farm output. The results have been published in [2].

A number of studies in the literature on $100 \%$ renewable energy use a short period of historical weather data, or a typical meteorological year (TMY), to determine the potential energy supply. However, studies like these do not capture the wide range of possible weather conditions that need to be considered for designing a reliable energy system. Therefore, there is a need to generate synthetic time series of GHI that include patterns of GHI that have not occurred in the recorded data, but are nonetheless likely to occur. We develop a method for generating synthetic daily and hourly GHI realisations.

A reliable electricity supply system will require a mix of renewable energy generators, distributed to take advantage of the spatial diversity of renewable power sources. We formulate the problem of finding the optimal mix of renewable energy sources with and without storage, and solve a simple example by finding the optimal scaling of 11 existing wind farms in South Australia to meet a short period of demand.

Finally, we examine the impact and viability of a household battery storage system using real household photovoltaic (PV) output and load profiles at high-resolution one-minute time scales, for 38 low-energy homes in Adelaide, South Australia. We simulate the operation of several levels of energy storage and calculate the impact on the amount and cost of imported electricity. We calculate the payback period for various energy storage configurations, and develop a method that can be used to estimate the ideal amount of storage for a household without requiring detailed data logs. The results have been published in [1, 5-7].

\section{References}

[1] J. Boland, F. Boulaire, A. Grantham and C. White, 'Optimisation of photovoltaic system and storage', ANZIAM J. $\mathbf{5 8}$ (2017), 1-32.

[2] A. Grantham, Y. R. Gel and J. Boland, 'Nonparametric short-term probabilistic forecasting for solar radiation', Solar Energy 133 (2016), 465-475.

[3] A. P. Grantham, P. J. Pudney, J. W. Boland and M. Belusko, 'Synthetically interpolated five-minute direct normal irradiance', in: 20th Int. Congr. Modelling and Simulation, Adelaide, Australia, 2013 1489-1495. https://www.mssanz.org.au/modsim2013/G1/grantham.pdf.

[4] A. P. Grantham, P. J. Pudney, L. A. Ward, M. Belusko and J. W. Boland, 'Generating synthetic five-minute solar irradiance values from hourly observations', Solar Energy 147 (2017), 209-221.

[5] A. Grantham, P. Pudney, L. A. Ward, D. Whaley and J. Boland, 'The viability of electrical energy storage for low-energy households', Solar Energy 155 (2017), 1216-1224.

[6] P. Pudney, A. P. Grantham, L. A. Ward, D. Whaley and J. Boland, 'The viability of electrical energy storage for Lochiel Park households', Cooperative Research Centre for Low Carbon Living, University of New South Wales and University of South Australia, 2016, 1-29.

http://www.lowcarbonlivingcrc.com.au/resources/crc-publications/crclcl-project-reports/rp1013viability-electrical-energy-storage-lochiel.

[7] D. Whaley, P. Pudney, A. Grantham and W. Saman, 'Performance of a cluster of low-energy housing rooftop PV systems: theoretical vs actual output', in: Proc. 52nd Annual Conf. (Australian Solar Energy Society, Melbourne, 2014), 63-72. 
ADRIAN GRANTHAM,

School of Information Technology and Mathematical Sciences,

University of South Australia, Mawson Lakes, South Australia 5095, Australia e-mail: adrian.grantham@unisa.edu.au 